\title{
Disciplinary Layout and Industrial Competitiveness Analysis in Colleges
}

\author{
Hua Wen \\ Chengdu University, Department of Business Administration, Chengdu, Sichuan, 610000
}

Keywords: Disciplinary Layout, Industrial Competitiveness, College Education

\begin{abstract}
Through the industrial agglomeration status, including the evolution of industrial structure, industrial layout and industrial restructuring, and higher education disciplines, including discipline structure, professional layout and curriculum system information, the paper through data analysis, determines the development of relations between them, the relevance and adaptability. It explores the industrial cluster and higher education disciplines layout of the fit between the degree of discovery of existing problems and deficiencies in both industry and education to offer solutions.
\end{abstract}

\section{Introduction}

Since the new century, China has generally reorganized the institutions of higher learning originally vested in ministries and commissions under the State Council. Some colleges have merged, while others have been transferred to the jurisdiction of local departments. Although the process of system reform in higher education is still smooth, some colleges still have a series of problems and shortcomings in the process of actual running. For example, professional settings can not effectively meet the needs of national or local economic development in our country or region, or can not The adjustment needs of the industrial structure in our country or place can be met; the assimilation of the target, discipline and professional structure caused by the long-term traditional mode of running education is becoming more and more assimilated, leading to the weakening of the core competitiveness of colleges; the lack of cross- , A direct impact on the employment of students after graduation, to reduce its social adaptability and so on. In recent years, with the continuous changes in the local industrial structure, local institutions, especially local industry and institutions, are gradually undergoing unusually severe tests. The enrollment enlargement of colleges and the increasing of the scale of higher education continue to increase, while the population of higher education of the right age shows a declining trend year by year and the competition for talent demand is getting fiercer, which will inevitably lead many local colleges to encounter problems in the professional structure construction The problem of attracting more students is, if not, a question mark for the survival and development of these institutions [1]. Coupled with the large-scale enrollment in recent years, hidden behind the low employment rate of local colleges, especially graduates of local industry colleges, the application of various professional training personnel and the ability to adapt to the society also appeared many unsatisfactory problems. Therefore, on this basis, the further adjustment of its professional structure and layout has become the top priority of the development of China's higher education.

\section{Analysis of Influencing Factors of Undergraduate Professional Structure Layout}

There are many factors influencing the structure and layout of higher education in one region or even a country. In a hierarchical sense, the factors of macro-level, medium-level and micro-level include the macro-level and the macro-level respectively. These three levels of factors restrict and limit the development path of higher education professional structure and layout to varying degrees. In this section, we will briefly introduce the various factors that affect the undergraduate professional structure and layout at different levels in the local industrial colleges. What is worth noting is that in previous studies, most of the studies focused on macro-industrial structural factors or microscopic of the institutions of higher learning itself to explain the changes in the professional structure of local industry institutions, this chapter from the mid-level factors selected from the 
population factors and social needs factors to be special instructions, hoping to add a unique perspective for the article.

For a period of time, the influence of the industrial structure of society on the setup and structural adjustment of tertiary education is obvious. In economics, the flow of resources and the continuous allocation of resources among the primary, secondary and tertiary industries are called changes in the industrial structure [2]. At present, our country is experiencing a new industrial revolution, that is, an era of transition from industrialization to informationization. Not open to the knowledge-driven economic development. In this way, in order to fulfill the important goal of promoting local economy in higher education, the professional structure of local industrial institutions must be consistent with the industrial structure of the place where they are located. Different from the era in which agricultural economy and industrial economy are the mainstay of industrial structure, the era of knowledge-based economy has a unique industrial structure: the proportion of agriculture continues to decline, the proportion of industries decreases significantly, the proportion of tertiary industry in total industries is obviously higher than the former two, To the intensive development of information, which on the number and quality of personnel put forward higher requirements [3]. Higher education not only aims at cultivating qualified personnel but also focuses on the production and application of knowledge. It is a unique social activity in the age of knowledge-based economy. This requires that the training objectives of our higher education must be balanced with changes in the industrial structure of society. This is also the embodiment of the principle of coordination of educational resources in educational ecology.

The micro-factors that affect the structural adjustment of higher education mainly refer to the influencing factors of a university itself, such as the self-positioning of the university, its own professional structure, what kind of resources it possesses, what kind of characteristics it has, Industry-related issues and the future development of the whole school. These are the micro-factors that affect the adjustment of the professional structure and layout of higher education institutions in a region.

\section{Undergraduate Professional Structure Layout Countermeasures and Suggestions}

As the frontier of scientific research, institutions of higher learning should not focus solely on theoretical research, especially in local industrial colleges. Therefore, it is necessary to clarify the thinking of development. In order to cultivate innovative and talented personnel, local industry and institutions in Shaanxi Province should closely integrate the discipline-based professional knowledge with practical teaching, and take the characteristic road combining production with study. The development of applied disciplines and the ability to translate theoretical knowledge from academic disciplines into productive forces have become the standard to evaluate the strength of research and application capabilities of local industry colleges. Local industrial colleges should focus on the construction of the industry, mainly on applied research and development, while paying attention to the transformation of scientific research achievements. They should also be guided by market demand and serve for the characteristics industries and the construction of social economy. And, from the faculty's point of view, local industry colleges in Shaanxi should strive to build a team of experienced teachers who have both rich theoretical knowledge and solid industry skills [4].

All kinds of resources of local industrial institutions include not only hardware facilities, such as schools, libraries, classrooms, etc., but also software facilities, that is, networks, databases, books, and literature. Economic theory holds that "resources are limited." Similarly, due to the scarcity of school resources, these resources are allocated to the construction of various professions. Conflicts often occur if they can not be rationally and effectively allocated. Using the economic game model to explain that assuming that two majors in one school share the same kind of educational resources, the two public majors can not use the educational resources at the same time due to the limited public teaching resources. The use of educational resources has a ceiling on the number of people who use them and once the number of people using them exceeds the upper limit, the quality of teaching in these two professions will be affected. The key to whether the professionals trained by 
colleges can adapt to the social construction and economic development lies in the connotation and quality of specialized disciplines with colleges. At present, as employers demand more and more jobs in colleges, college graduates will have more and more pressure to graduate from employment. Only when market demands are guided by the market demand can colleges improve graduates' Employment rate, the only way it will college professional structure and social and economic development to adapt to the layout. Therefore, the local industrial colleges must strengthen the connotation construction of disciplines in teaching. While paying attention to the specialization of specialties, it also strengthens the comprehensiveness of the professional layout, effectively improves the overall level of professionals, improves the quality of graduates and enriches the students' When the scope of knowledge-based learning, and strengthen students' ability to adapt to the survival of society, so as to ultimately enhance the core competitiveness of local industry colleges.

\section{Enhance the Competitiveness of the Discipline Management Recommendations}

According to the theoretical knowledge of disciplinary competitive advantage, we can see that due to the different resources and abilities each subject has, it leads to the difference of disciplinary competition. The discipline's competitiveness is mainly created through the resources and disciplines possessed by the discipline. Therefore, university administrators can improve discipline competitiveness by improving discipline resources and subject capabilities.

First, university administrators can improve the discipline's competitiveness by innovating in disciplinary organization. It is the fundamental purpose to carry out the innovation of subject organization by enhancing the ability of discipline, improving the efficiency of discipline management, reducing the cost of subject management and further enhancing the competitive advantage of subject. Disciplinary innovation in disciplines can be achieved through structural and institutional innovations. Discipline development shows the trend of separation, but also to a certain extent, the cross. With the extensive use of modern information technology, the management mode is undergoing a revolutionary change. Before the discipline lies a new development opportunity. Being able to respond quickly to new changes is a test for every discipline. In the face of new opportunities, if disciplines can make an advanced response, then there will be a new improvement in the ability of disciplines, and thus the competitiveness of disciplines will be promoted [5].

Second, university administrators can enhance their competitiveness with their competitors by differentiating their strategies. Each discipline is a unique organization, there are no two identical disciplines. Because of the differences between disciplines, disciplines can use this difference to find their place in an effort to gain a competitive advantage over the different. The big difference between the social demand for higher education products in this big market is the fundamental reason for the formation of interdisciplinary differences. Based on a thorough study of social needs and competitors, discipline managers should look for differences and differentiate means competitiveness. Disciplines can be differentiated from three aspects. First of all, it is the differentiation of the development goals of the subject. The most distinctive place in each subject is its development goals, which represent the future direction of the discipline and the most individualized indicator. Each discipline should have its own development goals that are different from those of other disciplines. At the same time, this development goal should be based on the actual situation of this subject rather than blindly follow different disciplines. In other words, discipline development should also have its own ideals and pursuits. Second, it is the difference between subject strength and subject structure. Discipline development also need to play a synergistic effect, not only need a good academic atmosphere, but also need to interdisciplinary cooperation and division of labor, to create the comprehensive advantages of the discipline. However, under the limited resources available to the university, it is almost impossible to establish all the disciplines. Which discipline to choose for development depends on the university's own capabilities and goals. Some are well-known in the world of universities, they are mainly science and engineering, or business-oriented, in short, have their own main direction. Lastly, it is the difference of choice of disciplinary development. In the choice of subjects, all universities should 
combine their own strengths, avoid weaknesses, so that limited academic resources and subject ability to play the greatest role.

University managers can take the opportunity to break the balance and enhance the competitiveness of disciplines. Among the competitive disciplines, some high reputation and strong disciplines are the makers of competition rules. Many common disciplines are the recipients of competition rules. Other emerging disciplines become the spoilers of the competition rules because they are unconstrained by tradition. Discipline's competitive position is not immutable, as new opportunities arise, strengths and weaknesses may be reversed. Because new opportunities mean that the original state of competition may be damaged, some new rules of competition may emerge. New moments such as changes in the international situation, changes in national policies, progress in science and technology, transition in economy and reforms in education often contain new opportunities. This is a great opportunity for disciplines to reverse their competitive position. The implementation of different policies and mechanisms will bring different gains and losses to the development of different disciplines. Therefore, discipline development should always be alert to changes in the environment in order to respond promptly as changes occur, seize opportunities and gain a competitive advantage.

\section{Conclusions}

This paper discusses competency theory and resource theory in the theory of competitive advantage, and on this basis, constructs a theoretical analysis framework of disciplinary competitiveness. The study concluded that the reason for the differences in the level of competency of disciplines is that each subject has different resources and abilities. The competitiveness of disciplinary resources and the competitiveness of disciplinary competence together constitute the competitiveness of disciplines. Human resources, material resources and intangible resources constitute the resources of three types of resources competitiveness; integration ability, learning ability and continuous innovation ability of the competitiveness of disciplines. Discipline capabilities are more important than subject resources in gaining a competitive advantage.

\section{Acknowledgements}

Key Research Base for Humanities and Social Sciences in Sichuan Province - Grant of Sichuan Education Research Center of West China Normal University Project Name: Sichuan Province Higher Education Discipline Layout and Industrial Cluster Adaptability Research, Project Number: CJF16007;

Key Research Base of Humanities and Social Sciences in Colleges of Sichuan Province --A Coordinated Urban and Rural Educational Development Research Center. Project Name: Adaptability Study of Disciplinary Layout and Industrial Development in Western China, Project No.: TCCXJY-2017-B06.

\section{References}

[1] Lu root book, Liu Min. Analysis of the Discipline Competitiveness and Discipline Construction in China's Universities [J]. Journal of Xi'an Jiaotong University, 2008 (6): 76-82.

[2] Teng Yuemin, Rong Shuan, Chen Hong. On Thoughts on Cultivating Approaches to Competitiveness in Disciplines - Concurrently on the Practice of Enhancing the Competitiveness of Printed and Publishing Disciplines [J]. Publishing in China, 2006 (10).: 82-86.

[3] Yi Kaigang. Humanities and social sciences a subject evaluation index system [J]. Advances in Science and Technology, 2008 (1) .142 -145.

[4] Barrow, C.W. The Strategy of Selective Excellence: Redesigning Higher Education for Global Competition in A Postindustrial Society [J]. Higher education, 1996. 83-88.

[5] Mansour Javidan. Core Competence: What Does It Mean in Practice. Elsevier, 2004 (31): 60-71. 